\title{
LINKAGE TO THE INCOMPATIBILITY FACTORS AND MAINTENANCE OF GENETIC VARIATION IN SELECTION LINES OF SCHIZOPHYLLUM COMMUNE
}

\author{
V. CONNOLLY' 1 and G. SIMCHEN ${ }^{2}$ \\ Department of Genetics, University of Birmingham, England
}

Received 18.xi.67

\section{INTRODUCTION}

IN a previous paper Simchen (1966) described the progress of selection over nine generations for high and low growth rate in the haploid progeny of a single dikaryon of Schizophyllum commune. Response to selection was observed in both directions for the first 3-4 generations. In later generations the two high and two low lines differed markedly in their behaviour. The high selection lines showed a rapid decrease in genetic variance and the progeny of the 8th generation were homogeneous. In contrast, both low lines maintained a high level of variation while response ceased. The low lines also showed a marked increase in evironmental variability which did not occur in the high lines.

Lack of response while considerable genetic variability is maintained for the character under selection is a common feature of many selection programmes (Reeve and Robertson, 1953; Clayton and Robertson, 1957, working with Drosophila; Lee and Pateman, 1961 ; Papa et al., 1967, selection in Neurospora; Falconer and King, 1953, selection in mice). In some instances selection of heterozygotes which are lethal or semi-lethal in the homozygous state and/or natural selection in the form of differential fertility operating against artificial selection have been shown to account for most if not all of the unfixable genetic variability observed.

In the present work selection was carried out at the haploid (monokaryon) phase, thus many of the machanisms by which genetic variability can be maintained at the diploid level such as selection of heterozygotes and other types of dominance interactions do not apply.

\section{MATERials AND METHODS}

The two low lines $L_{1}$ and $L_{2}$ have been continued to the 16th and 15 th generations respectively. Reverse selection was commenced at the 13 th generation to give two further lines designated $\mathrm{BL}_{1-13}$ and $\mathrm{BL}_{2-13}$. In addition two other lines $\left(M_{1}\right.$ and $\left.M_{2}\right)$ have been selected from the progeny of the same original dikaryon (isolate No. 2) which gave rise to the two high and two low lines. $\mathbf{M}_{1}$ and $\mathrm{M}_{2}$ are intermediate selection lines and were produced by selecting the two compatible monokaryons (full sib haploids) which had growth rates nearest the mean of their generation as parents for the next cycle of selection.

1 Present address: Agricultural Institute, Oak Park, Carlow, Ireland.

2 Present address: Genetics Laboratory, The Hebrew University, Jerusalem, Israel. 
Dikaryons were fruited in Petri-dishes on SF medium at $18^{\circ} \mathrm{C}$. under continuous illumination by "daylight" fluorescent tubes. When fruit bodies formed the Petri-dish was inverted over another Petri-dish containing malt medium. The inverted dish was rotated slowly for a short period, usually 5-10 seconds, depending on the number and size of the fruit bodies. The spread of basidiospores obtained in this way was incubated at $25^{\circ} \mathrm{C}$. for approximately 30-35 hours. The small colonies were then picked off under a dissecting microscope and transferred to malt Petri-dishes-five colonies per plate.

Mating types of monokaryotic progeny were determined by the method of Papazian (1950). Monokaryon testers, $A 3 B 3, A 3 B 4, A 4 B 4, A 4 B 3$, representing the four major groups of progeny obtainable from dikaryon No. 2, were mated to each unknown monokaryon. All four test matings being carried out on the same Petri-dish, the unknown monokaryon was inoculated in the centre as a control. Mating type determination was carried out on SCM medium (for details of the various media used see Simchen and Jinks, 1964). All experiments were assessed at $25^{\circ} \pm 0.5^{\circ} \mathrm{C}$. "Growth rate" was measured as the linear growth of the fungus in millimetres over a period of ten days in growth tubes.

Each experiment consisted of two randomised blocks, estimates of genetic and environmental components of variation could therefore be obtained for each generation. The rate of inbreeding was the same as that in previous experiments, i.e. two compatible full sib monokaryons were selected as parents of the next generation in each line. This mating system is equivalent to selfing plus assortative mating.

\section{ThE SELEGTION LINES}

The first two generations of $\mathrm{M}_{1}$ and $\mathrm{M}_{2}$ have been grown together, therefore $M_{1}$ and $L_{1}$ were randomised in the same experiment, similarly $L_{2}$ and $\mathrm{M}_{2}$ were grown together. In tables 1 and 2 the analysis of variance for each generation is given.

\section{(i) Intermediate selection lines}

Both $\mathbf{M}_{1}$ and $\mathbf{M}_{2}$ behave very much as would be expected under such intense inbreeding. $\mathbf{M}_{1}$ is a little faster growing than $\mathbf{M}_{2}$, a relationship it maintains during all the generations. Figures 1 and 2 show the frequency distributions for each generation, in fig. 3 the relative magnitudes of the genetic component $\left(V_{G}\right)$ and the environmental component $\left(V_{E}\right)$ are shown graphically. The expectations of mean squares on which these estimates are based are the same as those given by Simchen (1966). The behaviour of $M_{1}$ and $M_{2}$ was similiar to that of the two high lines $\left(H_{1}\right.$ and $\left.H_{2}\right)$ previously reported by Simchen (1966). Both lines showed rapid loss of genetic variation (fig. 3 ) which was fully exhausted by the 8th generation for $\mathbf{M}_{1}$ and almost so for $\mathbf{M}_{2}$. The error component $\left(\mathrm{V}_{E}\right)$ was less than that of the corresponding low line with which each generation was grown except for $\mathrm{M}_{2-3}$ which had a higher error estimate than $\mathrm{L}_{2-11}$.

All the parental monokaryons of each generation were stored in stock bottles at $5^{\circ} \mathrm{C}$. All of these were grown in the same experiment, thus making it possible to compare the different generations in a common 


\section{TABle 1}

Analysis of variance of each generation of $L_{1-10}$ to $L_{1-16}$ (low selection) $M_{1-1}$ to $M_{1-8}$ (intermediate selection) and $B L_{1-13(1)}$ to $B L_{1-13(3)}$ (reverse selection of $L_{1}$ )

\begin{tabular}{|c|c|c|c|c|c|c|}
\hline \multirow[b]{2}{*}{ Generation } & \multicolumn{2}{|c|}{ Between progeny } & \multicolumn{2}{|c|}{ Between blocks } & \multicolumn{2}{|c|}{ Error } \\
\hline & d.f. & M.S. & d.f. & M.S. & d.f. & M.S. \\
\hline $\mathrm{L}_{1-10}$ & 48 & $51 \cdot 47 * * *$ & 1 & $8 \cdot 58$ & 48 & $10 \cdot 77$ \\
\hline $\mathrm{L}_{1-11}$ & 49 & $37 \cdot 90 * *$ & 1 & $0 \cdot 36$ & 49 & $15 \cdot 92$ \\
\hline $\mathrm{L}_{1-12}$ & 49 & $67 \cdot 65 * * *$ & 1 & $6 \cdot 76$ & 49 & $14 \cdot 54$ \\
\hline $\mathrm{L}_{1-13}$ & 44 & $35 \cdot 48 * * *$ & 1 & $14 \cdot 40$ & 44 & $6 \cdot 92$ \\
\hline $\mathrm{L}_{1-14}$ & 49 & $40 \cdot 89 * * *$ & 1 & $30 \cdot 25$ & 49 & $19 \cdot 45$ \\
\hline $\mathrm{L}_{1-15}$ & 48 & $30 \cdot 22 * *$ & 1 & $0 \cdot 01$ & 48 & $9 \cdot 10$ \\
\hline $\mathrm{L}_{1-16}$ & 110 & $48 \cdot 91 * * *$ & 1 & $161 \cdot 77 * * *$ & 110 & $7 \cdot 48$ \\
\hline $\mathrm{BL}_{1-13(1)}$ & 49 & $10 \cdot 08 * *$ & 1 & $43 \cdot 56 * *$ & 49 & $4 \cdot 56$ \\
\hline $\mathrm{BL}_{1-13(2)}$ & 49 & $12 \cdot 77 * * *$ & 1 & $1 \cdot 44$ & 49 & $3 \cdot 05$ \\
\hline $\mathrm{BL}_{1-13(3)}$ & 48 & $6 \cdot 96$ & 1 & $0 \cdot 26$ & 48 & $5 \cdot 42$ \\
\hline$M_{1-1}$ & 94 & $67 \cdot 38 * * *$ & 1 & $12 \cdot 13 *$ & 94 & $2 \cdot 58$ \\
\hline$M_{1-2}$ & 46 & $107 \cdot 37 * * *$ & 1 & $1 \cdot 29$ & 46 & $2 \cdot 59$ \\
\hline$M_{1-2}$ & 44 & $112 \cdot 01 * * *$ & 1 & $22 \cdot 50$ & 44 & $10 \cdot 50$ \\
\hline$M_{1-4}$ & 47 & $31 \cdot 78 * * *$ & 1 & $7 \cdot 59$ & 47 & $8 \cdot 08$ \\
\hline$M_{1-5}$ & 45 & $41 \cdot 58 * * *$ & 1 & $90 \cdot 01 * * *$ & 45 & $5 \cdot 21$ \\
\hline$M_{1-6}$ & 49 & $7 \cdot 64$ & 1 & $75 \cdot 69 * * *$ & 49 & $5 \cdot 55$ \\
\hline$M_{1-7}$ & 48 & $14 \cdot 60 * * *$ & 1 & $4 \cdot 50$ & 48 & $4 \cdot 41$ \\
\hline $\mathbf{M}_{1-8}$ & 49 & $1 \cdot 30$ & 1 & $11 \cdot 56 * *$ & 49 & $1 \cdot 27$ \\
\hline
\end{tabular}

* Significance of $0 \cdot 05$. ** Significance of $0 \cdot 01$. *** Significance of $0 \cdot 001$.

\section{Table 2}

Analysis of variance of each generation of $L_{2-10}$ to $L_{2-16}$ (low line) $M_{2-1}$ to $M_{2-8}$ (intermediate line) $B L_{2-13(1)}$ to $B L_{2-13(2)}$ (reverse selection line of $L_{2}$ )

\begin{tabular}{|c|c|c|c|c|c|}
\hline \multicolumn{2}{|c|}{ Between progeny } & \multicolumn{2}{|c|}{ Between blocks } & \multicolumn{2}{|c|}{ Error } \\
\hline d.f. & M.S. & d.f. & M.S. & d.f. & M.S. \\
\hline 46 & $40 \cdot 48 * * *$ & 1 & $3 \cdot 84$ & 46 & $6 \cdot 73$ \\
\hline 46 & $98 \cdot 40 * * *$ & 1 & $27 \cdot 67$ & 46 & $8 \cdot 50$ \\
\hline 37 & $97 \cdot 72 * * *$ & 1 & $4 \cdot 26$ & 37 & $16 \cdot 05$ \\
\hline 45 & $57 \cdot 15 * * *$ & 1 & $0 \cdot 88$ & 45 & $15 \cdot 55$ \\
\hline 49 & $132 \cdot 65 * * *$ & 1 & $8 \cdot 41$ & 49 & $23 \cdot 90$ \\
\hline 84 & $60 \cdot 48 * * *$ & 1 & $33 \cdot 67$ & 84 & $16 \cdot 71$ \\
\hline 49 & $117 \cdot 49 * * *$ & 1 & 0.81 & 49 & $14 \cdot 34$ \\
\hline 80 & $56 \cdot 75 * * *$ & 1 & $95 \cdot 61 *$ & 80 & $19 \cdot 71$ \\
\hline 94 & $67 \cdot 38 * * *$ & 1 & $12 \cdot 13 *$ & 94 & $2 \cdot 58$ \\
\hline 49 & $26 \cdot 14 * * *$ & 1 & $12 \cdot 96 *$ & 49 & $3 \cdot 12$ \\
\hline 49 & $22 \cdot 13$ & 1 & $79 \cdot 21 *$ & 49 & $15 \cdot 17$ \\
\hline 39 & $8 \cdot 06$ & 1 & $25 \cdot 31 *$ & 39 & $5 \cdot 52$ \\
\hline 49 & $9 \cdot 13^{* * *}$ & 1 & $0 \cdot 25$ & 49 & $2 \cdot 19$ \\
\hline 49 & $4 \cdot 55$ & 1 & $50 \cdot 41 * *$ & 49 & $5 \cdot 12$ \\
\hline 47 & $4 \cdot 14$ & 1 & $6 \cdot 00$ & 47 & $2 \cdot 28$ \\
\hline 49 & $3 \cdot 39 * * *$ & 1 & $0 \cdot 64$ & 49 & 0.86 \\
\hline
\end{tabular}

* Significance $0 \cdot 05$. 


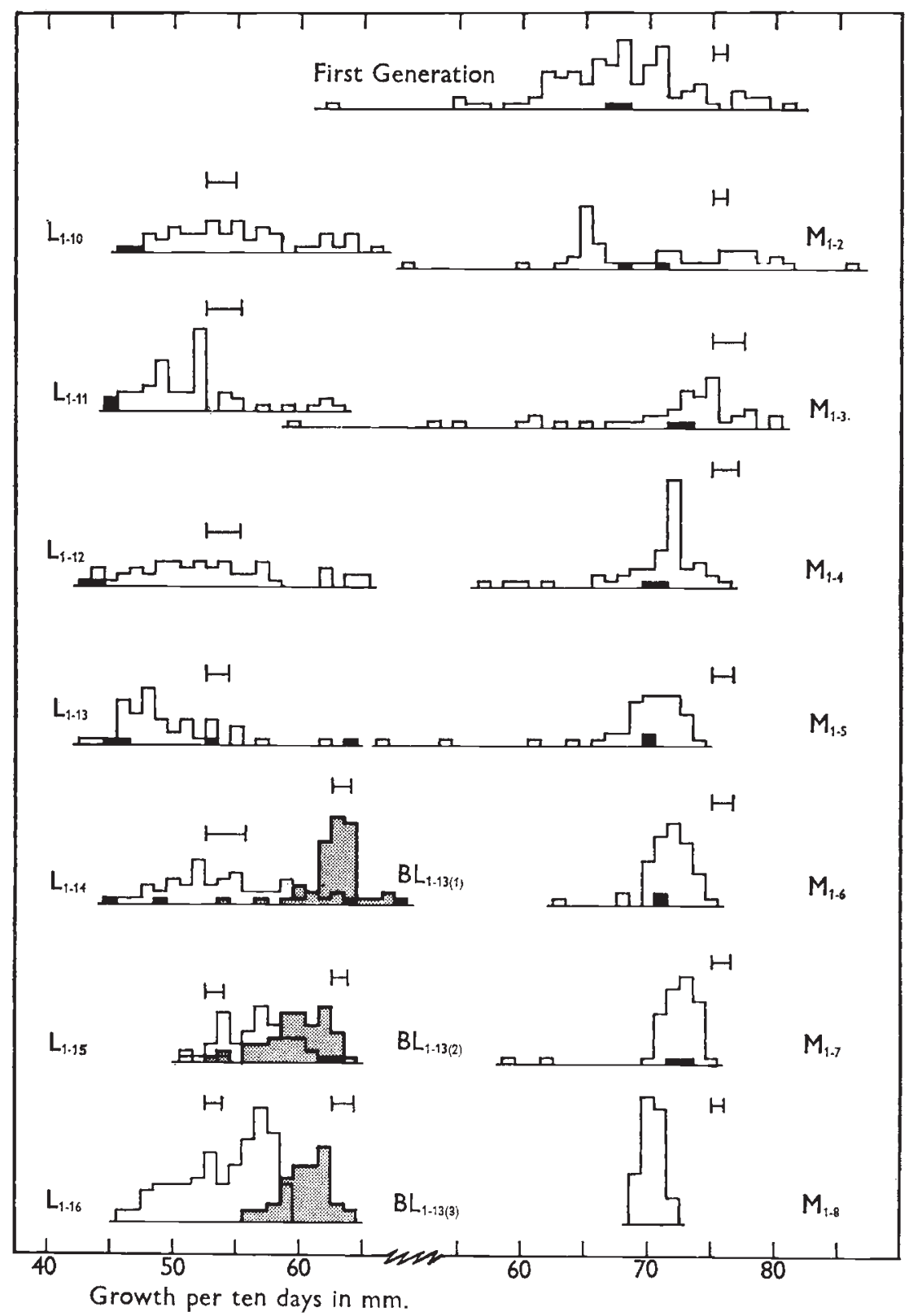

Fig. 1.-Frequency distributions of the haploid progeny of $L_{1}, B L_{1}$ and $M_{1}$ selection lines. The black squares indicate the monokaryons which were chosen as parents of the following generation. $|-|$ indicates the standard deviation of a single individual.

environment. The results are shown in fig. 4. This overcomes to a large extent differences between generations which were assessed under slightly different conditions, i.e. differences which could arise from different batches of media, slight differences in length of experiment (10 days $\pm 4 \mathrm{hr}$.) minor fluctuations in temperature, etc. 


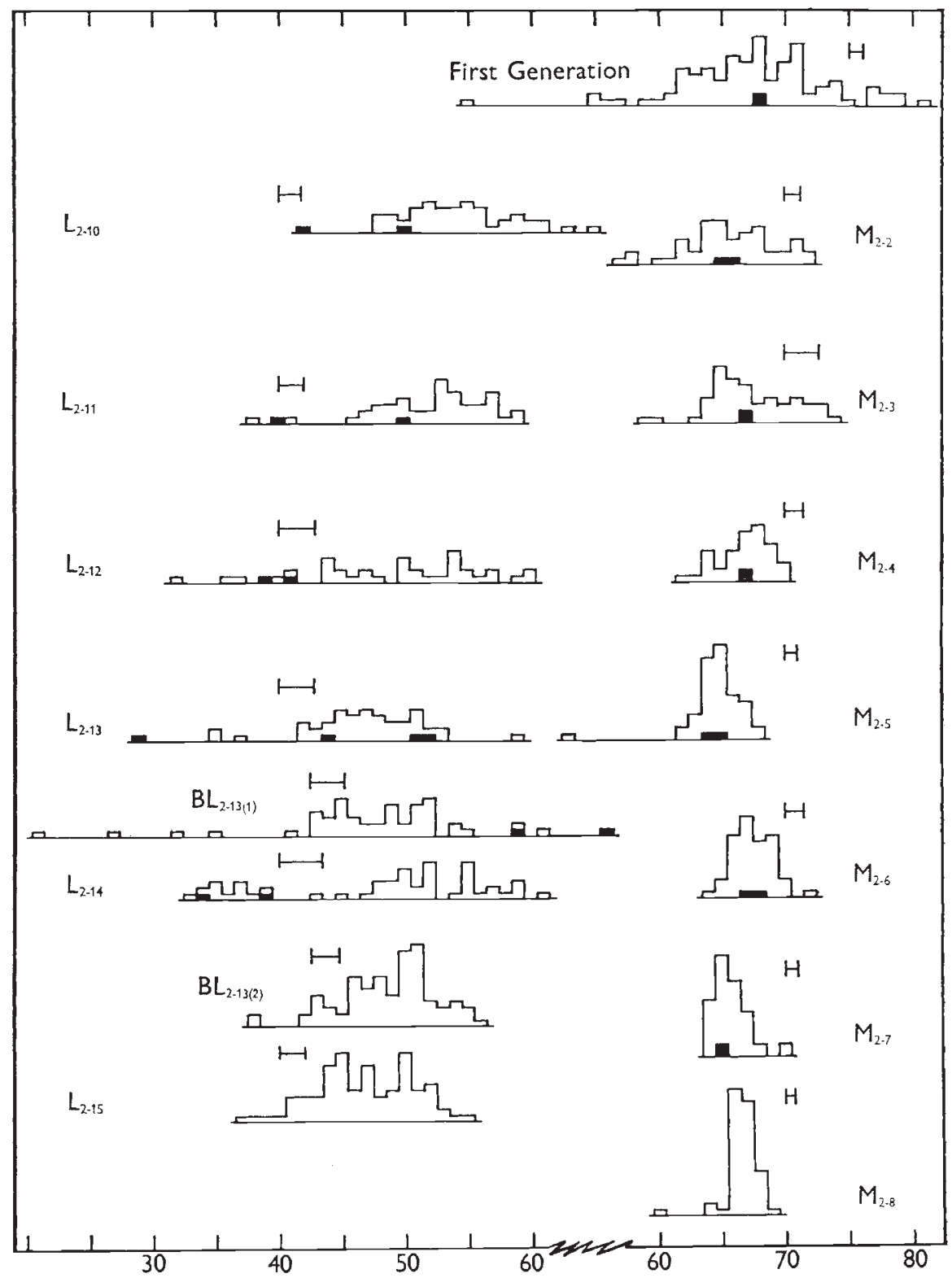

Growth per ten day in $\mathrm{mm}$.

Fig. 2.-Frequency distributions of the haploid progeny of $L_{2}, B L_{2}$ and $M_{2}$ selection lines. The block squares indicate the monokaryons which were chosen as parents of the following generation. $|-|$ indicates the standard deviation of a single individual.

(ii) Low selection lines

Both $\mathrm{L}_{1}$ and $\mathrm{L}_{2}$ continued to show high genetic variance, no response to selection and a high degree of instability.

These three characteristics (see figs. 1, 2, 3 and tables 1 and 2) have 
previously been reported by Simchen (1966) for the first nine generations. Estimates of the genetic component of variance tend to be higher in $\mathrm{L}_{2}$ than $\mathrm{L}_{1}$ and it is frequently higher than that of the original base population (i.e. first generation progeny of isolate No. 2). A similar phenomenon was noted by Clayton and Robertson (1957) in their low line female selection for abdominal chaeta number in Drosphila.

\section{(iii) Reverse selections}

These behaved rather differently, $\mathrm{BL}_{1}$ showing:

(a) immediate response,

(b) decrease in genetic variability,

(c) decrease in the environmental component of variation (see fig. 3).

This line appeared to be homogeneous in respect of the genes affecting growth at the 3 rd generation of reverse selection.

$\mathrm{BL}_{2}$ on the other hand behaved very like its parent line in all its characteristics, namely:

(a) no response,

(b) high genetic variance,

(c) high instability.

They were similar also in that the compatible monokaryons selected in the 15 th generation of $\mathrm{L}_{2}$ and the 2 nd generation of $\mathrm{BL}_{2}$ failed to produce fruit bodies.

In the frequency diagram of figs. 1 and 2 the individual genotypes of $\mathrm{L}_{1-15}$ and $\mathrm{L}_{1-16} \mathrm{BL}_{2-13(2)}$ and $\mathrm{L}_{2-15}$ are based on the means of four observations (two blocks plus two duplicates) in all other generations each individual is based on the mean of two. This accounts for the reduced standard errors given for the above four generations.

\section{Maintenance of Genetic VARIABILITy}

The major problem posed by the low selection lines is: what mechanisms operate to maintain genetic variability in the presence of such intense inbreeding? It is possible that some gene or genes affecting growth rate may be closely linked to the mating type factors and/or the instability associated with these two lines may make simple selection ineffective. If, as suggested by Simchen (1966), the L genotypes are particularly sensitive to environmental effects in the early stages of growth, which persist during later development, this would give rise to pseudo-genetic variation.

\section{(a) Within selection lines}

\section{(i) Linkage}

The $A$ and $B$ mating type factors are each composed of two loci $A \alpha, A \beta$; and $B \alpha, B \beta$ (Raper et al., 1958, 1960; Koltin, et al. 1967).

Since compatibility of any two monokaryons requires different specificities in both $A$ and $B$ factors it is necessary to maintain these in the heterozygous state during selection. Furthermore, where recombinants occurred between the $\alpha$ and $\beta$ loci these monokaryons were not selected. Thus the 


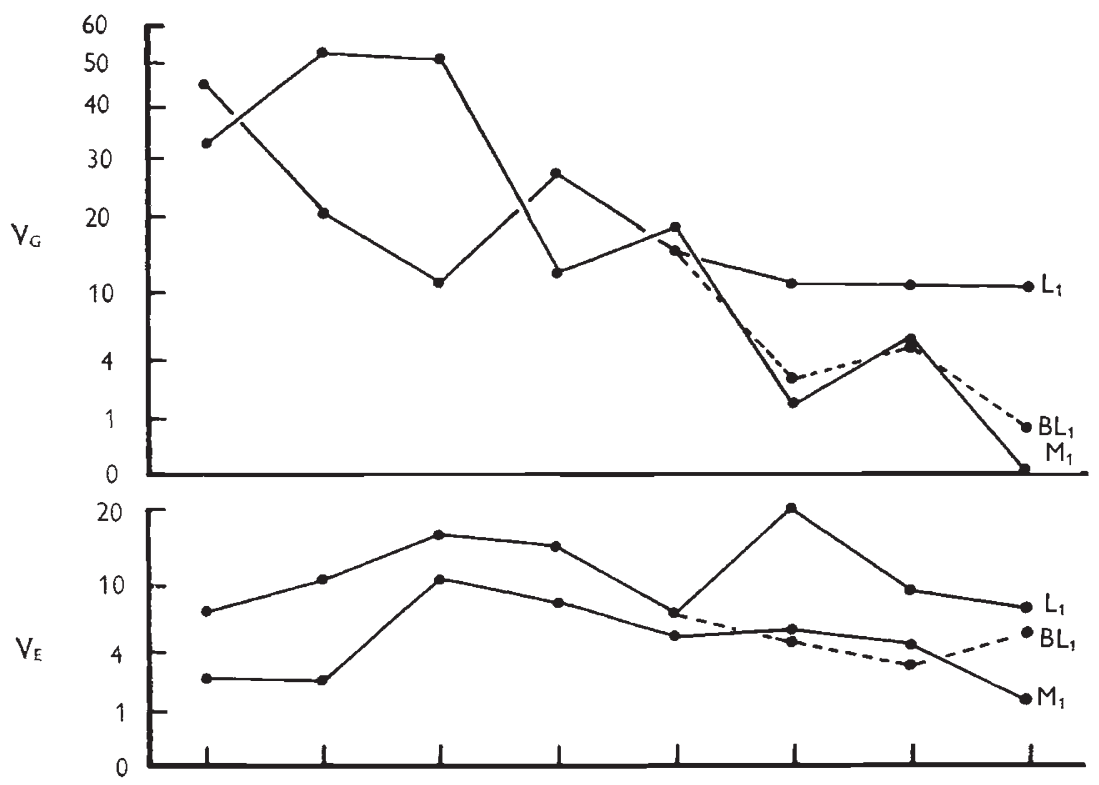

Generation
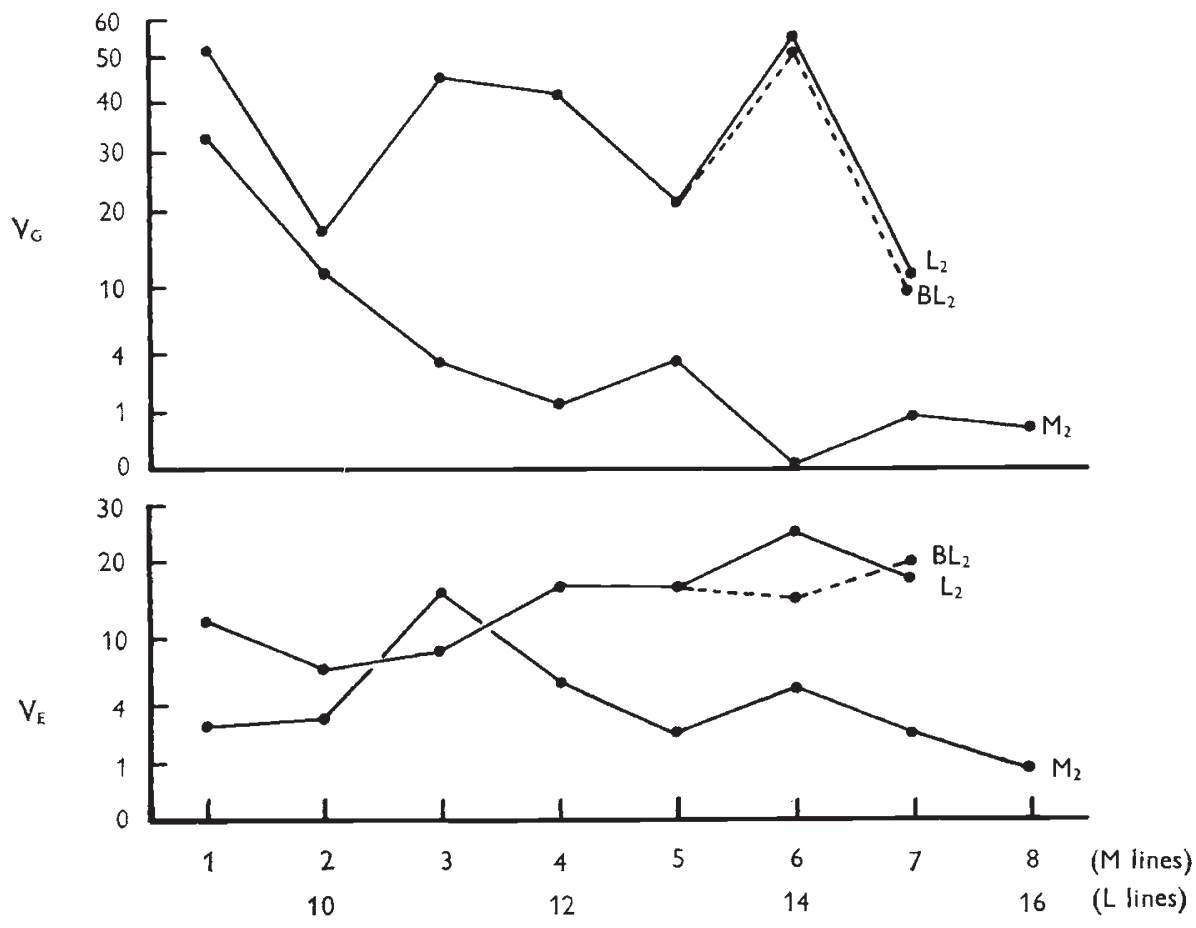

Generation

FIG. 3.-The changes in the components of variation for each generation. $V_{G}$ is the estimate of the heritable component and $V_{E}$ is the estimate of the environmental component of variation. 
chromosomal segment in the $\alpha-\beta$ region of each mating type factor has been maintained in the heterogeneous state (disregarding the possible occurrence of rare double crossovers in such a short segment).

Simchen (1966) has shown that genes affecting growth rate were linked to the $B$ factor in the progeny of three different isolates of Schizophyllum commune, but he did not find linkage in the progeny of isolate No. 2. He did, however, find linkage in at least one of the crosses $\left(\mathrm{L}_{1} \times \mathrm{H}_{1}\right)$ between the selection lines derived from this isolate.

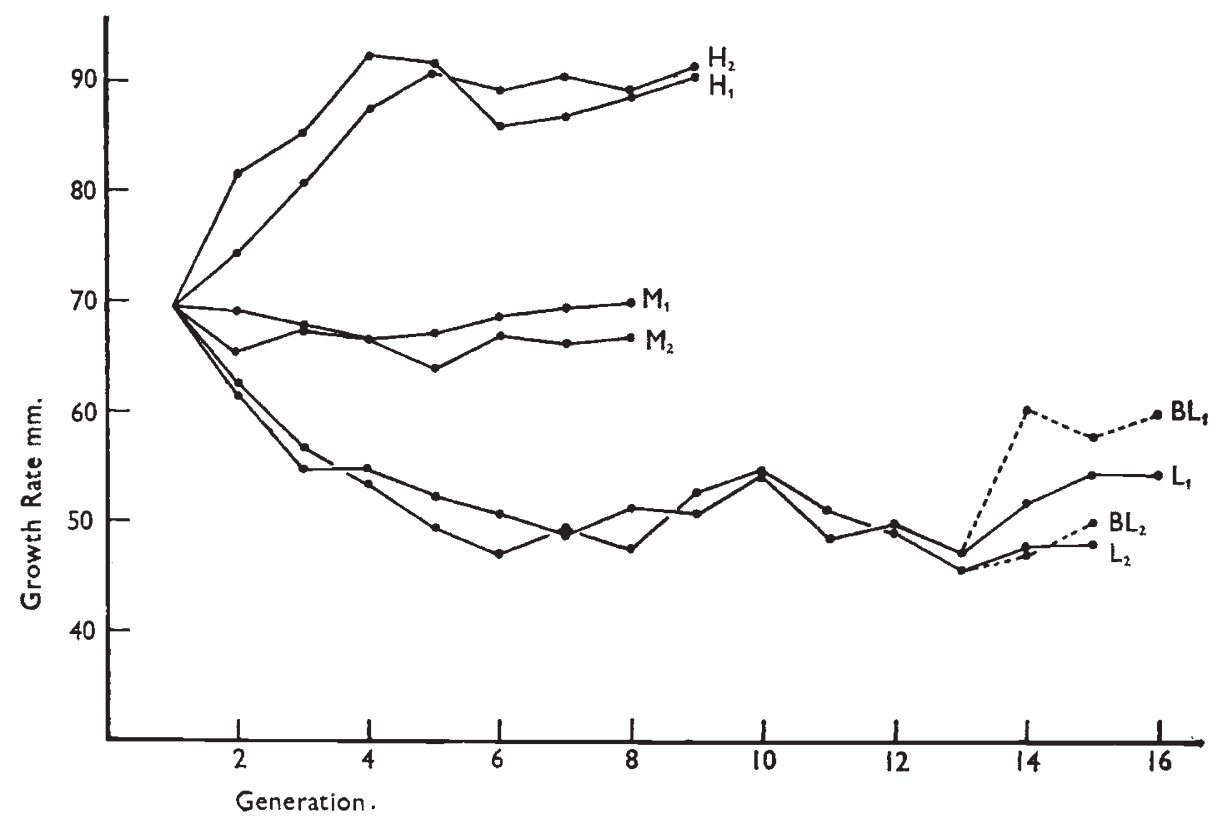

Fig. 4.-Relative growth rates of each generation for all selection lines (including $H_{1}$ and $H_{2}$ : Simchen, 1966) when grown in the same experiment.

In the 13th and later generations the mating type of all the monokaryons have been determined in $L_{1}, L_{2}$, and $B_{2}$. Only one generation of $B_{1}$ was assayed in this way. Comparisons can therefore be made between the different mating type groups. Significant differences between mating type groups would constitute evidence for linkage to the mating type factors. (We assume for the present that the mating type loci themselves have no effect on growth rate.) The numbers of individuals in the four mating type groups were not equal (although not deviating significantly from $1: 1: 1: 1)$ and a least squares analysis appropriate to unequal groups was employed. The results are summarised in table 3 , the duplicates item of this table will be discussed later. There are $3 d . f$. for comparisons between the four mating type groups; 1 d.f. for linkage to $A$ (i.e. $A 3$ v. $A 4$ ), 1 d.f. for linkage to $B$ (i.e. $B 3$ v. B4), 1 d.f. for the interaction between $A$ and $B$. The latter component was found to be significant (at the 5 per cent. level) in only 1 out of 20 experiments, it is assumed therefore that there is no interaction present. This component has been combined with the "within mating type" genetic variation to give what Simchen (1966) calls the Genetic Remainder. 
Linkage to the $B$ factor in $\mathrm{L}_{1}$ is consistent over the last three generations, that factor increasing growth rate being linked to $B 3$. In the last generation, $\mathrm{L}_{\mathbf{1 - 1 6}}$, there is also evidence of linkage to $A 3$.

\section{TABle 3}

Analysis of growth rates for linkage to mating type factors

(1) Within selection lines

(Block M.S. has been omitted from this table)

\begin{tabular}{|c|c|c|c|c|c|c|c|c|c|}
\hline \multirow{3}{*}{$\begin{array}{l}\text { Selection } \\
\text { line and } \\
\text { generation } \\
\text { number }\end{array}$} & \multirow{3}{*}{$\begin{array}{c}\text { Linkage } \\
\text { to } A \\
1 \text { d.f. } \\
\text { M.S. }\end{array}$} & \multirow[t]{2}{*}{$\begin{array}{c}\text { Linkage } \\
\text { to } B \\
1 \text { d.f. }\end{array}$} & \multicolumn{2}{|c|}{$\begin{array}{l}\text { Genetic } \\
\text { remainder }\end{array}$} & \multicolumn{2}{|c|}{$\begin{array}{c}\text { Duplicates } \\
\text { within }\end{array}$} & \multicolumn{2}{|c|}{ Error } & \multirow{3}{*}{ Notes } \\
\hline & & & & & & & & & \\
\hline & & M.S. & d.f. & M.S. & d.f. & M.S. & d.f. & M.S. & \\
\hline $\mathrm{L}_{1-13}$ & $103 \cdot 665$ & $2 \cdot 415$ & 35 & $35 \cdot 098 * * *$ & - & 一 & 37 & $6 \cdot 532$ & - \\
\hline $\mathrm{L}_{1-14}$ & 0.964 & $458 \cdot 112 * * *$ & 39 & 31.968 & - & - & 41 & $22 \cdot 233$ & $B 3>B 4$ \\
\hline$L_{1-15}$ & $26 \cdot 527$ & $153 \cdot 706 *$ & 38 & $30 \cdot 747 *$ & 41 & $15 \cdot 671 *$ & 81 & $10 \cdot 081$ & $B 3>B 4$ \\
\hline $\mathrm{L}_{1-16}$ & $266 \cdot 268 *$ & $384 \cdot 731^{* *}$ & 95 & $42 \cdot 410^{*}$ & 98 & 8.908* & 195 & $6 \cdot 422$ & $\begin{array}{l}A 3>A 4 \\
B 3>B 4\end{array}$ \\
\hline $\mathrm{BL}_{1 \cdot 13(1)}$ & $21 \cdot 718$ & 0.000 & 41 & $10 \cdot 274 * *$ & - & - & 43 & $4 \cdot 394$ & - \\
\hline $\mathrm{L}_{2-13}$ & $140 \cdot 072$ & $374 \cdot 721 * *$ & 39 & $43 \cdot 579 * *$ & 一 & 一 & 41 & $16 \cdot 013$ & $B 3>B 4$ \\
\hline $\mathrm{L}_{2-14}$ & $83 \cdot 155$ & 54.991 & 46 & $134.993 * * *$ & - & - & 48 & $24 \cdot 190$ & - \\
\hline $\mathbf{L}_{2-15}$ & $46 \cdot 809$ & $31 \cdot 739$ & 78 & $61 \cdot 016 * * *$ & 81 & $12 \cdot 099$ & 161 & $16 \cdot 016$ & - \\
\hline $\mathrm{BL}_{2-13(1)}$ & $130 \cdot 798$ & 0.000 & 43 & $120 \cdot 491 * * *$ & - & - & 45 & $14 \cdot 307$ & - \\
\hline $\mathrm{BL}_{2-13(2)}$ & $376 \cdot 742 * *$ & 3.939 & 75 & $52 \cdot 960 * *$ & 78 & $36 \cdot 353 * *$ & 155 & 23.076 & $A 3>A 4$ \\
\hline
\end{tabular}

* Significance $0 \cdot 05-0 \cdot 01$. ** Significance 0.01-0.001. $\quad * * *$ Significance $<0 \cdot 001$.

TABLE 4

Estimates of components of variance

(1) Within selection lines

\begin{tabular}{|c|c|c|c|c|c|}
\hline $\begin{array}{l}\text { Selection line and } \\
\text { generation number }\end{array}$ & $\hat{\sigma}_{\mathrm{LA}}^{2}$ & $\hat{\sigma}_{\mathbf{L B}}^{2}$ & $\hat{\sigma}_{\mathrm{R}}^{2}$ & $\hat{\sigma}_{\mathrm{D}}^{2}$ & $\hat{\sigma}_{e}^{2}$ \\
\hline $\begin{array}{l}\mathrm{L}_{1-13} \\
\mathrm{~L}_{1-14} \\
\mathrm{~L}_{1-15} \\
\mathrm{~L}_{1-16}\end{array}$ & $\begin{array}{l}0 \cdot 00 \\
0 \cdot 00 \\
0 \cdot 000 \\
1 \cdot 144\end{array}$ & $\begin{array}{r}0.00 \\
10.170 \\
1.500 \\
1.794\end{array}$ & $\begin{array}{r}14 \cdot 283 \\
4 \cdot 868 \\
3 \cdot 769 \\
8.376\end{array}$ & $\begin{array}{c}- \\
\overline{2} \cdot \overline{795} \\
1 \cdot 243\end{array}$ & $\begin{array}{r}6 \cdot 532 \\
22 \cdot 233 \\
10 \cdot 081 \\
6 \cdot 422\end{array}$ \\
\hline $\begin{array}{l}\mathrm{L}_{2-13} \\
\mathrm{~L}_{2-14} \\
\mathrm{~L}_{2-15}\end{array}$ & $\begin{array}{l}0.00 \\
0 \cdot 00 \\
0 \cdot 00\end{array}$ & $\begin{array}{l}7 \cdot 885 \\
0 \cdot 00 \\
0 \cdot 00\end{array}$ & $\begin{array}{l}13 \cdot 778 \\
55 \cdot 402 \\
11 \cdot 114\end{array}$ & $\overline{-}$ & $\begin{array}{l}16 \cdot 013 \\
24 \cdot 190 \\
16 \cdot 016\end{array}$ \\
\hline $\begin{array}{l}\mathrm{BL}_{2-13(1)} \\
\mathrm{BL}_{2-13(2)}\end{array}$ & $\begin{array}{l}0 \cdot 00 \\
2 \cdot 216\end{array}$ & $\begin{array}{l}0 \cdot 00 \\
0 \cdot 00\end{array}$ & $\begin{array}{r}53 \cdot 092 \\
5 \cdot 044\end{array}$ & $\overline{6 \cdot \overline{639}}$ & $\begin{array}{l}14 \cdot 307 \\
23 \cdot 076\end{array}$ \\
\hline
\end{tabular}

There is evidence of linkage to the $B$ factor in $\mathrm{L}_{2-12}$ and to the $A$ factor in $\mathrm{BL}_{2-13(2)}$. It must be remembered that the genetic remainder M.S. is used to test the significance of the linkage M.S., therefore our test of linkage is not very sensitive when the " background " genetic variation, as measured by the genetic remainder M.S., is high. This may be the reason for the inconsistency of the linkage tests in later generations of $\mathrm{L}_{2}$ and the 1st generation of $\mathrm{BL}_{2}$. 
Estimates of components of variation due to linkage are given in table 4 . The expectations of mean squares from which these estimates are obtained

$\begin{array}{ll}\text { Linkage to } A & \sigma_{e}^{2}+2 \sigma_{\mathbf{R}}^{2}+4 n \sigma_{\mathrm{LA}}^{2} \\ \text { Linkage to } B & \sigma_{e}^{2}+2 \sigma_{\mathbf{R}}^{2}+4 n \sigma_{\mathrm{LB}}^{2} \\ \text { Genetic remainder } & \sigma_{e}^{2}+2 \sigma_{\mathbf{R}}^{2} \\ \text { Error } & \sigma_{e}^{2}\end{array}$

$n$ being the number of progeny in each mating type group and there are two observations (two blocks) for each progeny (four observations for each progeny where we have duplicates). The mating type groups were not exactly equal, $2 n$ was therefore substituted by adjusted values calculated after Snedecor (1956, pp. 269-270) for unequal groups in the analysis of variance.

In the generations where duplicates are present the expectations are:

$\begin{array}{ll}\text { Linkage to } A & \sigma_{e}^{2}+2 \sigma_{\mathrm{D}}^{2}+4 \sigma_{\mathbf{R}}^{2}+8 n \sigma_{\mathrm{LA}}^{2} \\ \text { Linkage to } B & \sigma_{e}^{2}+2 \sigma_{\mathrm{D}}^{2}+4 \sigma_{\mathbf{R}}^{2}+8 n \sigma_{\mathrm{LB}}^{2} \\ \text { Genetic remainder } & \sigma_{e}^{2}+2 \sigma_{\mathrm{D}}^{2}+4 \sigma_{\mathbf{R}}^{2} \\ \text { Duplicates } & \sigma_{e}^{2}+2 \sigma_{\mathrm{D}}^{2} \\ \text { Error } & \sigma_{e}^{2}\end{array}$

The estimates indicate that at least for the $\mathrm{L}_{1}$ line a considerable portion of the genetic variability for growth rate can be attributed to linkage to the incompatibility factors.

\section{(b) Crosses between selection lines}

Crosses between selection lines were carried out in duplicate, the origin of the mating type factors in the second being the reverse of that of the first cross. For example in the case of $\mathrm{M}_{1-8} \times \mathrm{L}_{1-16}$ the first cross is $A 3 B 4 \times A 4 B 3$, and the second cross is $A 4 B 3 \times A 3 B 4$. The monokaryons $A 3 B 4$ and $A 4 B 3$ taken from the 8 th generation of $M_{1}$ are homogeneous with respect to genes controlling growth rate (see table 1, fig. 3); they are used therefore as testers in these crosses.

In this series of experiments the mating type of the progeny was determined before growth rate measurements were made. It was therefore possible to have equal numbers in all four mating type groups, thus making the analysis of variance and estimation of components easier.

The results from these crosses, which are summarised in table 5, show highly significant linkage in all crosses to one or both of the incompatibility factors. Linkage to $A$ in the cross $\mathrm{BL}_{1-13(3)} \times \mathrm{L}_{1-16}$ is of border-line significance. It is also evident that the incompatibility factors themselves do not have any effect on growth rate-this has previously been assumed. To take one example, in the cross $\mathrm{M}_{1-8} \times \mathrm{BL}_{2-13(2)}$ the factor conditioning faster growth is linked to $A 3$, in the reciprocal cross it is the group containing $A 4$ which has the faster mean growth rates. Similar results are shown for the $B$ factor in the cross $\mathrm{L}_{2-15} \times \mathrm{L}_{1-16}$.

A simple model for the example discussed above might be:

$$
\begin{array}{llllll}
\multicolumn{2}{c}{\mathbf{M}_{1-8}} & & \multicolumn{2}{c}{\mathrm{BL}_{2-13(2)}} \\
A 3^{+} & B 4 & \times & A 4^{-} & B 3 \\
A 4^{+} & B 3 & \times & A 3^{-} & B 4
\end{array}
$$


This means that different alleles ( + and - ) are fixed in the two inbred parent lines. In other crosses such as $\mathrm{M}_{1-8} \times \mathrm{L}_{1-16}$ where one of the duplicate crosses shows linkage but the other does not, a model such as the following could be used:

\begin{tabular}{llll}
\multicolumn{2}{c}{$\mathrm{M}_{1-8}$} & \multicolumn{2}{c}{$\mathrm{L}_{-1-16}$} \\
$A 3$ & $B 4^{+}$ & $A 4$ & $B 3^{-}$ \\
$A 4$ & $B 3^{+}$ & $A 3$ & $B 4^{+}$
\end{tabular}

TABLE 5

Analysis of growth rates for linkage to mating type factors

(2) Crosses between lines

(Blocks M.S. have been omitted from this table)

\begin{tabular}{|c|c|c|c|c|c|c|c|c|}
\hline & & $\begin{array}{l}\text { Linkage } \\
\text { to } A \\
(1 \text { d.f. })\end{array}$ & $\begin{array}{l}\text { Linkage } \\
\text { to } B \\
\text { (1 d.f.) }\end{array}$ & & $\underbrace{\text { enetic }}_{\text {ainder }}$ & $\begin{array}{r}\text { Er } \\
(= \\
\times \mathrm{Ger} \\
\end{array}$ & $\begin{array}{l}\text { rror } \\
\text { Blocks } \\
\text { notype) }\end{array}$ & \\
\hline monokaryon & of parents & M.S. & M.S. & d.f. & M.S. & d.f. & M.S. & Notes \\
\hline $\begin{array}{c}\mathrm{M}_{\mathrm{I}-8} \\
\times \mathrm{BL}_{2-13(2)} \\
\text { do }\end{array}$ & $\begin{array}{l}A 3 B 4 \times A 4 B 3 \\
A 4 B 3 \times A 3 B 4\end{array}$ & $\begin{array}{r}1080 \cdot 21 * * * \\
708 \cdot 27 * * *\end{array}$ & $\begin{array}{c}2 \cdot 38 \\
270 \cdot 27^{*}\end{array}$ & $\begin{array}{l}81 \\
89\end{array}$ & $\begin{array}{l}36 \cdot 56 * * * \\
56 \cdot 23 * * *\end{array}$ & $\begin{array}{l}83 \\
91\end{array}$ & $\begin{array}{l}4 \cdot 83 \\
5 \cdot 18\end{array}$ & $\begin{array}{l}A 3>A 4 \\
A 4>A 3 \\
B 4>B 3\end{array}$ \\
\hline $\mathrm{M}_{1-8} \times \underset{\mathrm{L}-16}{\mathrm{~L}_{1-16}}$ & $\begin{array}{l}A 3 B 4 \times A 4 B 3 \\
A 4 B 3 \times A 3 B 4\end{array}$ & $\begin{array}{l}1.02 \\
0.00\end{array}$ & $\begin{array}{c}270 \cdot 75 * * * \\
11 \cdot 50\end{array}$ & $\begin{array}{l}93 \\
89\end{array}$ & $\begin{array}{l}20 \cdot 22 * * * \\
22 \cdot 95 * * *\end{array}$ & $\begin{array}{l}95 \\
91\end{array}$ & $\begin{array}{l}5 \cdot 63 \\
4 \cdot 10\end{array}$ & $B 4>B 3$ \\
\hline $\mathrm{M}_{1-8} \times \frac{\mathrm{L}_{2-15}}{\mathrm{do}}$ & $\begin{array}{l}A 3 B 4 \times A 4 B 3 \\
A 4 B 3 \times A 3 B 4\end{array}$ & $\begin{array}{l}1859 \cdot 00 * * * \\
1002 \cdot 27 * * *\end{array}$ & $\begin{array}{r}4 \cdot 45 \\
87 \cdot 36\end{array}$ & $\begin{array}{l}85 \\
85\end{array}$ & $\begin{array}{l}36 \cdot 39 * * * \\
39 \cdot 11 * * *\end{array}$ & $\begin{array}{l}87 \\
87\end{array}$ & $\begin{array}{l}9 \cdot 59 \\
5 \cdot 46\end{array}$ & $\begin{array}{l}A 3>A 4 \\
A 4>A 3\end{array}$ \\
\hline $\mathrm{L}_{2-15} \times \mathrm{L}_{1-16}$ & $A 3 B 4 \times A 4 B 3$ & $445 \cdot 56 * *$ & $150 \cdot 16$ & 77 & $58 \cdot 96 * * *$ & 79 & $7 \cdot 63$ & $\begin{array}{l}A 4>A 3 \\
B 4>B 3\end{array}$ \\
\hline $\mathrm{BL}_{1-13(3)}^{\text {do }} \times \mathrm{L}_{1-16}$ & $\begin{array}{l}A 4 B 3 \times A 3 B 4 \\
A 3 B 4 \times A 4 B 3 \\
A 4 B 3 \times A 3 B 4\end{array}$ & $\begin{array}{c}435 \cdot 60 * \\
124 \cdot 69 \\
54 \cdot 06\end{array}$ & $\begin{array}{r}105 \cdot 63 \\
56 \cdot 25 \\
0 \cdot 76\end{array}$ & $\begin{array}{l}77 \\
69 \\
77\end{array}$ & $\begin{array}{l}87 \cdot 30 * * * \\
34 \cdot 22 * * * \\
28 \cdot 64 * * *\end{array}$ & $\begin{array}{l}79 \\
71 \\
79\end{array}$ & $\begin{array}{l}5 \cdot 74 \\
7 \cdot 48 \\
7 \cdot 69\end{array}$ & $\begin{array}{l}A 3>A 4 \\
A 3>A 4\end{array}$ \\
\hline
\end{tabular}

TABLE 6

Means and estimates of components of variance

(2) Crosses between lines

\begin{tabular}{|c|c|c|c|c|c|}
\hline $\begin{array}{c}\text { Parental } \\
\text { monokaryon }\end{array}$ & $\begin{array}{l}\text { Mating type } \\
\text { of parents }\end{array}$ & d.f. & $\hat{\sigma}_{\mathrm{LA}}^{2}$ & $\hat{\sigma}_{\mathrm{LB}}^{2}$ & $\hat{\sigma}_{\mathbf{R}}^{2}$ \\
\hline $\mathrm{M}_{1-8} \times \mathrm{BL}_{2-13(2)}$ & $A 3 B 4 \times A 4 B 3$ & 6 & $12 \cdot 424$ & 0.000 & $15 \cdot 864$ \\
\hline & $A 4 B 3 \times A 3 B 4$ & 6 & $7 \cdot 087$ & $2 \cdot 326$ & $25 \cdot 525$ \\
\hline $\mathrm{M}_{1-8} \times \mathrm{L}_{1-16}$ & $A 3 B 4 \times A 4 B 3$ & & 0.000 & $2 \cdot 610$ & $7 \cdot 2$ \\
\hline & $A 4 B 3 \times A 3 B 4$ & & 0.000 & 0.000 & $9 \cdot 427$ \\
\hline $\mathrm{I}_{1-8} \times \mathrm{L}_{2-15}$ & $A 3 B 4 \times A 4 B 3$ & 6 & $20 \cdot 711$ & 0.000 & $13 \cdot 404$ \\
\hline & $A 4 B 3 \times A 3 B 4$ & 6 & $10 \cdot 945$ & 0.000 & \\
\hline $\mathrm{L}_{2-15} \times \mathrm{L}_{1-16}$ & $A 3 B 4 \times A 4 B 3$ & 14 & 4.832 & $1 \cdot 140 \dagger$ & 25.667 \\
\hline & $A 4 B 3 \times A 3 B 4$ & 14 & $4 \cdot 354$ & 0.000 & $40 \cdot 781$ \\
\hline $\mathrm{BL}_{1-13(3)} \times \mathrm{L}_{1-16}$ & $A 3 B 4 \times A 4 B 3$ & 14 & $1 \cdot 257 \dagger$ & 0.000 & $13 \cdot 372$ \\
\hline do & $A 4 B 3 \times A 3 B 4$ & 14 & 0.000 & 0.000 & $10 \cdot 47$ \\
\hline
\end{tabular}

$\dagger$ Tests of significance of appropriate M.S. do not reach the 5 per cent. level.

This model implies that one of the parents, in this instance the low line as expected, is segregating for the linked factor.

The gene or polygenic block affecting growth rate which is linked to the $A$ factor although showing considerable variation between crosses has a much larger effect than that linked to the $B$ factor (see tables 5 and 6 ). 
The estimates of linkage components show rather good agreement between reciprocal crosses.

\section{(ii) Instability-split spores and hyphal tip experiments}

In all of the analyses described so far the genetic remainder component is highly significant. Sensitivity to environment in the very early stages of the young mycelium could give rise to pseudogenetic variation if such early effects persist in later growth. In order to test this possibility the young mycelium was split into duplicate pieces under a dissecting microscope as early as possible after germination, which proved to be after 21-22 hr. incubation at $25^{\circ} \mathrm{G}$. Generations $\mathrm{L}_{1-15}, \mathrm{~L}_{1-16}, \mathrm{~L}_{2-15}$ and $\mathrm{BL}_{2-13(2)}$ were treated in this way. The analysis of the growth rates of the duplicate pieces are given in table 3 . $\mathrm{L}_{1}$ (both generations) and $\mathrm{BL}_{2}$ show significant differences between duplicates, but no evidence for such an effect could be found in $L_{2-15}$. These results lend support for the above hypothesis-that sensitivity to environment at an early stage in development could result in spurious genetic variation.

TABLE 7

Analysis of hyphal-tip variation

\begin{tabular}{|c|c|c|c|c|c|c|c|c|c|}
\hline$A$. Genotypes & 14 & $69 \cdot 17$ & $* * *$ & 15 & $192 \cdot 10$ & $* * *$ & 15 & $149 \cdot 77$ & **** \\
\hline $\begin{array}{l}B . \text { Hyphal tips } \\
\text { within }(A)\end{array}$ & 75 & $15 \cdot 94$ & * & 80 & $15 \cdot 55$ & $*$ & 80 & $10 \cdot 14$ & $* *$ \\
\hline C. Blocks & 1 & $4 \cdot 36$ & $\longrightarrow$ & 1 & $16 \cdot 92$ & - & 1 & $0 \cdot 63$ & - \\
\hline$A \times C$ & 14 & $17 \cdot 81$ & - & 15 & $14 \cdot 32$ & - & 15 & $4 \cdot 46$ & - \\
\hline$B \times C$ & 74 & $11 \cdot 21$ & - & 79 & $11 \cdot 08$ & - & 80 & $5 \cdot 02$ & - \\
\hline
\end{tabular}

Hyphal tips were taken from haploid colonies of generation $L_{1-16}, L_{2-15}$ and $\mathrm{BL}_{2-13(1)}$. The number of colonies established from these hyphal tips was small, minimum number being six. The six hyphal tip colonies derived from each of 47 genotypes were grown together in the same experiment. In $\mathrm{L}_{1-16}$ differences between hyphal tips derived from the same genotype are highly significant (see table 7). In $\mathrm{L}_{2}$ and $\mathrm{BL}_{2}$ the significance of this item is borderline. The effects observed here may have a similar orgin to that observed for duplicates. Both the duplicate and hyphal tip differences could also be due to cytoplasmic segregation; no distinction between the two cases can be made on the evidence available.

\section{(iii) Spore germination}

Spore germination was estimated for each generation for all the selection lines by microscopic examination of malt agar plates on which spores were spread rather densely and incubated at $25^{\circ} \mathrm{G}$. for $14-16 \mathrm{hr}$. The results are summarised in table 8.

Both $\mathrm{L}_{2}$ and $\mathrm{M}_{1}$ show rather low spore germination, low germination was also found for progeny of dikaryons produced by random mating 
monokaryons derived from the original dikaryotic isolate. Differential viability of the spores could limit the response to selection by eliminating extreme genotypes; it could not, however, maintain genetic variation under full sib gametic selection unless the genes controlling the expression of the character were also linked to the incompatibility factors. The fact that no significant deviation from the normal $1: 1: 1: 1$ ratio of the four mating type groups was found in all generations tested would indicate that the low germination observed in these two lines was independent of mating type.

TABle 8

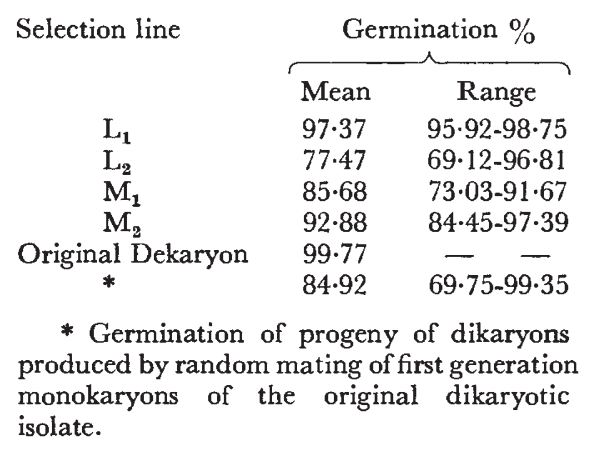

\section{Discussion}

The intermediate selection lines do not require much further comment, they behave very much as would be expected under such an intense inbreeding system. The rate of decrease of genetic variation, the stage at which the inbreds become homogeneous and the high level of stability are all similar to that found for the high selection lines (Simchen, 1966).

The analysis of the low selection lines indicate that some of the residual heterogeniety is due to linkage of genes affecting growth rate to the mating type factors. If we assume that the same loci control growth rate in all the selection lines then the degree of linkage must not be such as to prevent fixation occurring in the two high and two intermediate lines. This is also supported by the response of the reverse selection of $\mathrm{L}_{1}$ which become homogeneous after three generations. The frequency of recombination between the mating type factors and genes controlling growth rate could have been reduced during selection of the low lines. The frequency of recombination in the $\alpha-\beta$ region of both the $A$ and $B$ mating type factors has been examined (Simchen and Connolly 1968). But in all cases either an increase in recombination frequency was found, or no change in intrafactor recombination relative to the original dikaryon could be detected. Although this is indirect evidence, it does indicate that no drastic reduction in recombination frequency appears to have occurred in this region of the chromosome.

The results of the linkage analysis for within selection lines and for crosses between these same lines and a common tester are not in agreement. Where the low line appears to be segregating for a factor which is linked to one or other of the incompatibility "loci", then we would expect to detect this in the cross to the tester line-- $\mathbf{M}_{1-8}$. We can also distinguish this type of linkage from that in which it is due to different phases of the same allele being 
fixed in the two parent lines (see earlier). In the latter case we would expect to find the linkage item significant in both crosses, but if we have the situation where the linked factor is in the heterogeneous state in the low parent, then we would expect linkage to be present in one cross only. The results of the crosses to $M_{1-7}$ are in many cases very different to what we expect from the analysis within the selection lines themselves. For example, in the cross $M_{1-8} \times L_{1-16}$ we expect the increasing factor to be linked to $B 3$ where in fact it is linked to $B 4$. In the crosses $M_{1-8} \times B_{2-13(2)}$ and $\mathrm{M}_{1-8} \times \mathrm{L}_{2-15}$ the results indicate that we are dealing with linkage of growth rate factors to the $A$ mating type " locus" but in each cross different phases of the same "allele" appears to be fixed in the $M_{1}$ and $L$ inbred lines. The significant linkage components observed in the analysis within the low lines themselves would suggest that "genes" affecting growth rate were segregating. These "genes" must either be inactive or have a much reduced effect in the crosses to the tester line. In all cases, however, we must bear in mind that the sensitivity of our linkage test is dependent on the magnitude of the residual within mating type genetic variation-as measured by the genetic remainder. In the cross $\mathrm{BL}_{1-13(3)} \times \mathrm{L}_{1-16}$ the linkage to $A$ M.S. is large but not significant. Analysis of the $\mathrm{L}_{1}$ inbred (table 3 ) shows consistent linkage to the $B$ factor and in the last generation $\left(\mathrm{L}_{1-16}\right)$ there is also linkage to $A$. There is no evidence of linkage to either factor in the analysis of $\mathrm{BL}_{1}$ as would be expected since this line became homogeneous for growth rate genes after three generations of reverse selection. In the cross between these lines, however, we are unable to detect linkage of significant effect. This cannot be attributed to a large genetic remainder in the cross between inbreds, it is in fact smaller than that recorded for the last generation of $\mathrm{L}_{1}\left(\mathrm{~L}_{1-16}\right)$.

Mather (1953) and Thoday $(1955,1958)$ have shown that instability as measured by asymmetry in the number of sternopleural chaetae produced on each side of Drosophilia melanogaster is under genetic control and is not a property of homozygosity per se. Analysis of Nicotiana data also supports this view (Jinks and Mather, 1955). In the present experiments only the two low lines show increased instability, the two high and two intermediate selection lines (which in fact are more homogeneous than the two low lines) show a very high degree of stability. This increased instability could arise from the breakdown of balanced gene complexes which control stability (Mather, 1953) or by direct selection of genes for instability. When stability is restored on crossing to stable lines it is possible that the indirect effect of these stability genes on the development of the character under selection may no longer be detectable. This could account for the difference in the linkage results obtained from the crosses between the inbred lines and those expected on the basis of the within line linkage analysis.

The instability associated with the low selections would make simple selection ineffective, as was found by Lee and Pateman (1961) in their selection for increased ascospore length in Neurospore. In the present experiments repeatability as measured by the correlation between measurements on the same genotype in different experiments is very low-for $\mathrm{L}_{1}, r_{(14)}=0.3117$; for $\mathrm{L}_{2}, r_{(14)}=0.4212$; for $\mathrm{BL}_{2}, r_{(13)}=0.3589$; none of which differ significantly from zero. In these circumstances linkage of genes affecting growth rate to the mating type factors would be difficult to break. 


\section{Summary}

1. Two low selection lines of Schizophyllum commune, previously inbred for nine generations, which continued to show genetic variation without response were inbred for a further seven generations. Reverse selection was initiated in the 13th generation in both selection lines. Selection was carried out at the haploid level.

2. Linkage analysis within the low selection lines indicated that some of the genetic variation was being maintained by linkage of genes controlling growth rate to the mating type factors.

Results of linkage analysis for crosses between the low lines and a tester line did not agree in some respects with those obtained from the within line analysis. Possible causes for this discrepancy are discussed.

3. The two low lines show a high level of instability making simple selection less efficient. Evidence from the analysis of hyphal tip and duplicate colony experiments indicates that part of the genetic variation is spurious in nature, or, alternatively, of cytoplasmic origin.

4. Reverse selection in $\mathrm{L}_{1}$ showed response and decrease in genetic and environmental components of variability while $\mathrm{BL}_{2}$ showed no detectable change from the parent line.

5. Selection for intermediate growth rate is described. The two lines $M_{1}$ and $M_{2}$ show rapid loss of genetic variation which is fully exhausted by the 8 th generation.

Acknowledgments.-We wish to thank Professor J. L. Jinks for his advice and encouragement during the course of this work and for reading the manuscript.

This work was carried out while one of us (V. C.) was on leave of absence from the Agricultural Institute, Garlow, Ireland, to whom he is grateful. This research was supported by the Agricultural Research Council of Great Britain.

\section{REFERENGES}

GLAYTON, G. A., AND ROBERTSON, A. 1957. An experimental check on quantitative genetical theory. II. The long term effects of selection. F. Genet., 55, 152-170.

FALCONER, D. S., AND KING, J. W. B. 1953. A study of selection limits in the mouse. F. Genet., 51,56 I-58I.

JINKS, J. L., AND MATHER, K. 1955. Stability in development of heterozygotes and homozygotes. Proc. Roy. Soc. B., 143, 561-578.

KOLTIN, Y., RAPER, J. R., AND SIMCHEN, G. 1967. The genetic structure of the incompatibility factors of Schizophyllum commune: B. factor. Proc. Natl. Acad. Sci., U.S., 57, 55-62.

LEe, B. T. O., AND Pateman, J. A. 1961. Studies concerning the inheritance of ascospore length in Neurospora crassa. Aust. Four. Biol. Sci., 14, 223-230.

MATHER, K. 1953. Genetical control of stability in development. Heredity, 7, 297-336.

PAPA, K. E., SRB, A. M., AND FEDERER, W. T. 1967. Inheritance of growth rate in Neurospora crassa: Reverse selection in an improved strain. Heredity, 22, 255-266.

PAPAzIAN, H. P. 1950. The physiology of the incompatibility factors of Schizophyllum commune. Bot. Gaz., 112, 143-163.

RAPER, J. R., BAXTER, M. G., AND EllinhoE, A. H. 1960. The genetic structure of the incompatibility factors of Schizophyllum commune: the A factor. Proc. Natl. Acad. Sci., U.S., $46,833-842$.

RAPER, J. R., BAXTER, M. G., AND MIDDLETON, R. B. 1958. The genetic structure of the incompatibility factors in Schizophyllum commune. Proc. Natl. Acad. Sci., U.S., 44, 899-900.

SIMCHEN, G. 1966. Monokaryotic variation and haploid selection in Schizophyllum commune. Heredity, 21, 241-263.

SIMCHEN, G., AND CONNOLLY, v. 1968. Changes in recombination frequency following inbreeding in Schizophyllum. Genetics, 58, 319-326. 
SIMCHEN, G., AND JINKS, J. L. 1964. The determination of dikaryotic growth rate in the basidiomycete, Schizophyllum commune: A biometrical analysis. Heredity, 19, 629-649. THodAy, J. M. 1955. Balance, heterozygosity and developmental stability. Cold Spr. Hrbr. Symp. Quant. Biol., 20, 318-326.

THODAY, J. м. 1958. Homeostasis in a selection experiment. Heredity, 12, 401-415. 